\title{
Reclaiming Kindergarten: Part I. Questions about Theory and Practice
}

\author{
Dominic F. Gullo • Kim Hughes
}

Published online: 9 November 2010

(C) Springer Science+Business Media, LLC 2010

\begin{abstract}
The purpose of this article is to describe the crisis that exists in kindergarten today related to maintaining developmentally and culturally appropriate practice while at the same time addressing the academic standards set forth by most states. In Part I, three questions are posed, the answers to which seek to elucidate possible solutions to this dilemma. The questions center on issues related to developmentally appropriate practice, intentional teaching, and assessment. Research and expert opinion associated to each of these areas are discussed, and examples of classroom practice are used to illustrate the effective implementation of these principles in a kindergarten classroom.
\end{abstract}

Keywords Kindergarten - Academic standards ·

Assessment $\cdot$ Developmentally appropriate teaching

Recently, Matthew's former prekindergarten teacher received an email from Matt's parents letting her know how he was adjusting to kindergarten in his new school. Matt's parents' remarked that he thought school was boring and that he didn't want to go, even though he thrived in prekindergarten. Matt told his parents that the teacher is just "teaching, teaching and teaching, there are no toys and we can't play and have fun."

Kindergarten has changed radically in the last two decades in ways that few Americans are aware of.

D. F. Gullo ( $\square)$

Drexel University, Philadelphia, PA, USA

e-mail: dfg28@drexel.edu

K. Hughes

Project Enlightenment, Wake County Public Schools, Raleigh, NC, USA
Children now spend far more time being taught and tested on literacy and math skills than they do learning through play and exploration, exercising their bodies, and using their imaginations. Many kindergartens use highly prescriptive curricula geared to new state standardized tests. In an increasing number of kindergartens, teachers must follow scripts from which they must not deviate. These practices, which are not grounded in research, violate longestablished principles of child development and good teaching.

This, according to the Alliance for Childhood (Miller and Almon 2009, p. 11), describes the landscape of today's kindergarten. A "crisis" they call it. The question is, can we take this crisis and turn it into an opportunity? An opportunity to reclaim kindergarten as a place where children are actively engaged in planned activities; activities that stimulate all their sensory modalities and pique their curiosity for learning, while at the same time, addressing the educational accountability issues so prevalent in today's society.

Reclaiming kindergarten involves an understanding of the multifaceted issues that comprise the interrelated associations of theory, research, practice and policy affecting kindergarten teaching. Consideration of any of these issues in isolation can manifest itself in kindergarten practices that are disadvantageous to ensuring that children, teachers and programs reach their optimum potential. In this two part editorial, questions will be raised-questions related to how theory, research, practice and policy can work synergistically so that this crisis in kindergarten can be turned into an opportunity to demonstrate that sacrificing what we know is good for children is not necessary to achieve high academic standards and developmentally 
appropriate teaching. Part I of this editorial will address issues related kindergarten practice, specifically curriculum, teaching and assessment. In Part II, two kindergarten policy questions will be the focus. The first question is related to the important role that families play, while the second is related to the changing role that kindergarten plays in the wider landscape of early childhood education. The latter suggests a paradigmatic shift in response to changes in societal realities and expectations.

\section{The Bar has been Raised}

In kindergarten today, the bar has been raised. Expectations for kindergarten children and their teachers have changed. This is due in part to the fact that more and more children are attending prekindergarten, and in some measure, due to state academic standards for kindergarten becoming increasingly widespread (Graue 2006). Since the 2001-2002 school year, the total enrollment for government funded prekindergarten programs has increased by $73 \%$ for four-year-olds and $45 \%$ for three-year-olds. In the United States, more than $80 \%$ of all four-year-olds attend some kind of prekindergarten program (NIEER 2008). For many children, kindergarten is no longer their first experience with school.

As a result, what is expected of kindergarten children and their teachers has changed. Kindergarten is no longer a place where children become familiar with the social expectations of formal schooling and where basic academic and group skills are introduced. Consequently, formal academic teacher-directed instruction has overshadowed the need for children's active learning based on socialization, imagination and creativity. Rather than an emergent and integrated kindergarten curriculum, the focus on curriculum development has become more narrowly defined. The emphasis has become content-oriented, skill-based instruction and learning that teachers assess using conventional measures. Worksheets or other paper and pencil teacher-made tests have become customary practice for determining what specific skills and knowledge children have acquired. In today's kindergarten, teachers and children alike are under great pressure to meet inappropriate expectations reflected in external academic standards that until now have been reserved for higher grades (Miller and Almon 2009).

While kindergarten has changed in ways that reshape curriculum and instructional practices that are more reminiscent of primary grades, the fundamental developmental characteristics of kindergarten children have not changed. The ways they construct knowledge and problem solve have not changed. The ways they learn have not changed. The ways they socially interact have not changed. Finally, the fact has not changed that, while there are many similarities among kindergarten-aged children, not all kindergartners learn at the same rate or in the same way. While in classrooms such as those described above, teachers often teach under the assumption that all children should know all the same things at the same time. The fact still remains that not all kindergartners learn at the same rate or in the same way (Berk 2006; Tomlinson 2009). The dilemma resulting from this confounding situation is: how do we make certain that all children have a kindergarten experience that makes it possible for all children to learn and succeed, while making certain that academic standards are met? In short, how do we ensure that all kindergarten children have a kindergarten experience that is "joyful" and filled with wonder?

According to the Merriam Webster Dictionary, "joyful" means "experiencing well-being, success, or good fortune." All those who touch the lives of young learners agree that they deserve a kindergarten experience that enables them to have a sense of well-being; that all children experience success; and all children have opportunities for good fortune. This, while at the same time, making certain that all kindergarten children meet the academic standards that will increase the likelihood of future school and personal success. The way we respond to this dilemma may lie in the way we respond to five interrelated questions about the kindergarten experience related to curriculum, teaching, assessment, family participation, and policy. The answers to these questions may shed light into ways that we can turn this burgeoning crisis into an opportunity. Part I of this editorial will focus on the first three questions.

It is important to note, that the responses to the questions must take into account the dynamic nature of the kindergarten experience that results from the changing political and social landscape, as well as the varied experiential changes that are taking place for many children before they enter kindergarten. At the same time, however, the responses to these questions must also take into account the fairly fixed nature of child development affecting how children at specific ages benefit from experiences, academic or otherwise.

Following the discussion of each question, Mrs. Wiseman, a seasoned kindergarten teacher (actually a conglomeration of many seasoned kindergarten teachers) will provide concrete classroom examples of how to apply the principles described in each of the responses. As will be seen, Mrs. Wiseman is cognizant of the fact that kindergarten children require learning experiences that take into account their developmental nature and varied experiential backgrounds, while at the same time is fully aware of the learning goals embedded in her kindergarten curriculum. 
Question \#1 What factors do we need to consider in preserving developmentally and culturally appropriate experiences for kindergarten children with regard to curriculum content, instructional strategies, and learning environments?

Children in kindergarten, while having common developmental attributes, also reflect wide variations in their development (Tomlinson 2009). Part of the variation has to do with characteristic differences in children's developmental trajectories related to differences in their biological maturation and experiential backgrounds; part of this variation in today's kindergarten has to do with the wider range of children's ages in kindergarten classrooms. While kindergarten primarily serves five-year-olds, kindergartners can range in age from $4 \frac{3}{4}$ to $7 \frac{1 / 4}{4}$ years (Berk 2006). These wide discrepancies in age may be due to the practice of redshirting children (the practice of holding children out of kindergarten for a year with the belief that they are too immature to attain academic success and will be more academically successful when they are older), differences in states' entrance age requirements, or due to some children being retained in kindergarten.

Another challenge that faces kindergarten teachers today has to do with the changing nature of the kindergarten population. Children who are now in kindergarten programs are no longer like those who were in these classrooms 20 years ago. The number of children who come from culturally or linguistically different backgrounds has increased dramatically. The National Center for Education Statistics (2002) reports that whites (non-Hispanic) comprise $63.5 \%$ of public school enrollment, with blacks (nonHispanic) accounting for $17 \%$, Hispanics for $14.4 \%$, Asian/ Pacific Islanders for $3.9 \%$, and American Indian/Alaskan natives for $1.2 \%$. Hernandez (2004) projects that between 2020 and 2030, more than half of all children in the United States will be from minority groups. This increase in the numbers of children who are culturally and/or linguistically diverse brings with it curriculum, teaching and assessment challenges.

More than ever, a "one size fits all" brand of kindergarten is no longer appropriate. Today's kindergarten classrooms must be able to serve the developmental, social, and academic needs of all children. This means that today's kindergarten curriculum and learning environments must reflect elements that are appropriate for "typical" kindergarten children, while at the same time reflect the appropriate variations in curriculum content and teaching strategies, that take into account the varied needs of individual children.

Mrs. Wiseman teaches 22, 5-year-olds in an urban public school setting with the support of a teaching assistant. She knows that positive relationships with both her students and their families are a key to her success with her students. She strives to be sensitive and responsive, as she affirms students' efforts, gives constructive feedback, and avoids negative interactions that shame children, so her students develop a sense of competence and confidence.

Home visits conducted early in the school year lay a foundation of understanding for, and appreciation of the diversity and strengths that each student brings to the kindergarten classroom. Careful observation and listening with eyes, ears, mind, and heart give Mrs. W. effective information to unconditionally know each student in order to successfully scaffold her curriculum. While acknowledging some developmental and cultural similarities among all of her kindergartners, she spends the beginning of their school year getting to know and appreciate the uniqueness that each child brings to his/her kindergarten classroom. Ongoing mechanisms such as their Morning Meetings create meaningful connections as the children share familiar songs, giggle about yesterday's field trip, assure personal space as each gives a classmate a "morning greeting," talk about what excites them and predict what the new day will bring. Mrs. W. does everything within her power to "know her children with her heart as well as she knows them intellectually" (Graue 2006 pp.3-10).

Differentiated learning is critical so she intentionally varies instructional strategies, materials, experiences and activities to guide children's learning and development. Mrs. W. recognizes the importance of choice. She carefully structures her learning activities and materials and encourages children to choose from among these. Mrs. W. uses active learning as an opportunity for children to construct their own knowledge and uses a variety of learning contexts and a balance of both child-initiated and teacher-directed activities to move her students forward. Her kindergarten classroom offers structure regarding both the organization of the environment and daily schedule of her students. Students trust the "sameness" of their kindergarten routine and the high expectations for learning.

Mrs. W. promotes a safe learning environment that encourages exploration, initiative, positive peer interaction and cognitive growth. Materials are chosen that challenge children's skills. Comfortable work areas are provided for interaction and collaboration, as well as spots for silent reading, construction projects, writing, playing math or language games 
and exploring science. This is a kindergarten classroom where learning really happens!

Question \#2 How do we maintain developmentally and culturally appropriate teaching while at the same time addressing academic standards?

Being an "excellent teacher" is at the core of the response to this question. The characteristics of excellent teaching are written about elsewhere (Copple and Bredekamp 2009), but central to excellent teaching is being intentional (Epstein 2007). Briefly, being an intentional teacher means that all aspects of teaching are carefully and purposefully thought out and the relationship to learning and program outcomes are clear from the start. Pianta (2003) defines intentionality in teaching as "directed, designed interactions between children and teachers in which teachers purposefully challenge, scaffold, and extend children's skills" (p. 5).

Berliner (1992) goes on to emphasize that, in order to teach effectively, teachers need to demonstrate intentionality in their instructional interactions with students. In addition, teachers need to be clear about expected student outcomes. In summarizing the research on the relationship between learning environments and learning outcomes, Berliner (1987, 1992) suggests the following characteristics are requisite:

Teachers should have high expectations for all students and expect that all children can learn by purposefully engaging children in learning activities to enhance their knowledge and skills.

Teachers should engage in planning and management in which they have concrete instructional plans to introduce content area information and sequence children's learning. Through appropriate planning and management, teachers should also be able to manage both individual behavior as well as group dynamics.

Teachers and children alike should see the value of a learning oriented classroom, where there is intention to teach and intention to learn.

Teachers understand both how children learn and what motivates them to learn. Through this understanding teachers use engaging activities to capture the interest of children and that reflect a connectedness to their own experiences and are at a level that is neither too easy nor too difficult for them to experience some level of success. Teachers need to engage in the process of thoughtful questioning in order to get insight into how children are thinking and to stimulate their construction of knowledge and problem solving.

Teachers need to understand when and how to use appropriate feedback to help students understand their own thinking and levels of development and attainment.
Early childhood educators have learned over the years that excellent teaching is not an "either/or" way of thinking. That is, "either" the teaching practice is developmentally appropriate "or" it is not. Rather, excellent teachers that are intentional know that teaching reflects a "both/and" approach to teaching (Copple and Bredekamp 2009). Being an excellent teacher means that teachers can teach "both" in a developmentally and culturally appropriate manner "and" teach so that academic standards are being met.

Mrs. Wiseman believes that children learn by doing and works diligently to embed standards-based learning objectives into rich, inquiry-based activities that are meaningful, interesting, and motivating to young children. During a recent unit on "things that move," Mrs. W. incorporated many kindergarten learning standards including measurement, estimating, collecting and organizing data, understanding of weather concepts, integration of various literacy skills, and much more. One afternoon she observes children playing during recess with a found bird feather, attempting to keep it air borne, varying their velocity of breaths of air. As the children's interest begins to wane, she wanders over and asks the children to estimate how many breaths it took to keep the feather air borne. Teacher and students then gather together to brainstorm and record ideas about other items that they might be able to keep air borne with their breaths of air or with other equipment. The next recess finds several of these suggestions concretely available for the children's enjoyment.

Children learn best through active engagement, through conversation, and dialogue concerning their experiences. Discovery involving concrete objects or manipulatives and multi-sensory experiences enhance learning in young children by helping them understand the world and how things work. Learning in this way is deeper, more meaningful, and offers a strong foundation for future learning.

For children, play is serious work and is an important vehicle to promote language, cognition, social competence, and self-regulation. The "bird feather" activity involves both children's discovery and teacher enhancement ... it combines both play and work ... it encapsulates both joy and increased awareness ... it balances both child-initiated and teacher-directed interactions that lead to a "give and take" of both learning and teaching.

Question \#3 How do we appropriately use assessment to inform curriculum and teaching in kindergarten? 
Assessment is often thought to be one of the primary reasons for inappropriate practices in kindergarten. Teachers often teach to the test or narrow the curriculum, teaching only those things that will be assessed on a test. Teachers may rely on drill and practice to ensure that children's performance on tests achieve predetermined standards, whether appropriate or not. But it doesn't have to be that way. When used appropriately, assessment can serve as a means of attaining and maintaining classroom practices that facilitate kindergarten children's learning. Assessment can inform teaching so that developmentally and culturally appropriate practices are preserved, while at the same time assuring that academic standards are being met (Gullo 2006). What follows are some assessment guidelines that demonstrate how assessment can assure accountability and at the same time take place in a classroom that reflects teaching strategies that are supportive of kindergarten children's developmental approach to learning (Gullo 2005).

\section{Assessment Should be a Continuous Process}

Ideally assessment is a means for measuring the progress of children's learning over time. There is no beginning, middle, or end to children's learning, so it follows that assessment of children's learning should not be limited to measuring learning only at the end of an instructional unit. It is important that we identify the learning sequences that children are mastering. We should also recognize that children are individually progressing through learning sequences. Not all children learn the same things at the same point at the same time. Learning is a continuum, and assessment can help to identify where each child is on this continuum.

\section{Assessment Should be a Comprehensive Process}

Many aspects of learning can and should be assessed. How well does the child know the facts? How does the child meaningfully use what they've learned? Can they apply their learning to other situations? Therefore, there are many contexts in which assessment should occur. Assessing only in one way or in one context does not tell us the whole story. When assessing children, we should use multiple sources of information, assess the multidimensional aspects of learning, and assess children in multiple learning contexts.

\section{Assessment Should be an Integrative Process}

The stated learning goals in the curriculum should guide our assessment process. What we assess and how we characterize assessment procedures should be related to children's learning experiences. Ideally, children should be assessed while engaged in the process of learning. This will result in two benefits. First, assessments can be used as tools for modifying the curriculum to meet individual children's strengths and needs. Second, assessment can be used as a measure of curriculum effectiveness.

Assessment informs curriculum and teaching by providing teachers with information about children's current levels of understanding as well as their developmental status. Teachers use this information to create and/or modify curriculum and teaching to meet the children's developmental and academic needs (Gullo 2006; Hughes and Gullo 2010). Assessment should be thought of as a process, and as such be ongoing, use multiple sources of information, be integrated with teaching and curriculum and provide a means to communicate with others, including families, about children. Importantly, assessment should take place while children are engaged in the process of learning. Assessment should not be used as a means of excluding children from experiences or used in ways not intended. We need to refocus the discussion on assessment away from one that focuses on high stakes testing to one that focuses on high performance assessment-where using assessment information has the potential to positively influence teaching, learning, and accountability. For as Gail Connelly, Executive Director of the National Association of Elementary School Principles states (2010), “applying a single measure like test scores to a complicated enterprise like educating children paints a one dimensional picture-a flat, shallow, and inaccurate snapshot when what we need is a three-dimensional portrait of the whole child. We can and should do a better job of capturing how students learn and grow: Socially, emotionally, and academically" (p. 3).

Mrs. Wiseman knows that frequent, embedded assessments should both guide instruction and be used to monitor progress. She also understands learning sequences and is acutely aware of the continuum of learning in each curriculum area. In her classroom, assessment and evaluation form the basis for educational decisions. Information about children's progress and needs are gained via observations so that she can then select materials that align with students' learning styles and developmental levels of learning. Ideally, Mrs. W. will then plan activities that respond to her kindergartners' interests, experiences and skills. She will ask thought provoking questions extending students' interest, thinking and learning. Intense observation, careful questioning, respectful listening and detailed record keeping offer a full understanding of every child's capabilities, facilitating authentic "teachable moments" and creating a springboard for a continuum of knowledge. 
Learning is personal, active and genuine; discovery invites mastery and empowerment, delight feeds passion and a quest for more; determination nurtures confidence and creates a sense that learning is forever. Mandated assessments are conducted in child-friendly, naturalistic environments whenever possible. These data are used to determine student mastery of learning standards and will drive future instructional dissemination.

Mrs. W. uses naturalistic data collection and assessments whenever possible. As the children arrive at school one morning, each student is asked to create a unique "ABAB" pattern using precut shapes as part of their morning routine. Mrs. W. observes Vasmi asking a peer, "What is an ABAB pattern?" During the children's Discovery Time, she invites Vasmi and a few other students over to the Math and More Center to experience some time exploring pattern blocks. After the student spends time "messing around," she steps into facilitate Vasmi's increased understanding about patterns. As they sort and transform a variety of patterns, she asks open-ended questions to encourage Vasmi's creation of a variety of $\mathrm{ABAB}$ patterns.

Days later, as she "kid watches" her students during Discovery Time, she makes note of several ABAB patterns that Vamsi creates with multicultural people in the sand table. Later that day, she overhears Vasmi tell a classmate that the line to go to lunch is an ABAB pattern as it finds a line of boy-girl-boy-girlboy-girl. Mrs. W. is now confident that Vasmi has mastered basic patterning and is ready for the next level of sequenced learning.

The bar has been raised. Societal expectations for kindergartners' academic performance has increased beyond laying the foundation for what lies ahead to expectations of learning narrowly focused, state mandated knowledge and skills, often to the detriment of teaching in a manner that is consistent with how young children learn. In Part I of this article, Mrs. Wiseman has shown us that teaching kindergarten in today's world is a science where academic expectations can be met and where teaching and assessing children can reflect an understanding of children's development, both collectively and individually. Part II finds Mrs. Wiseman further reinforcing this premise as we explore two kindergarten policy questions focusing on both the essential role that families play, as well as the changing role that kindergarten plays in the wider landscape of early childhood education.

\section{References}

Berk, L. E. (2006). Looking at kindergarten children. In D. F. Gullo (Ed.), K Today: Teaching and learning in the kindergarten year (pp. 11-25). Washington, DC: NAEYC.

Berliner, D. C. (1987). Simple views of effective teaching and a simple theory of classroom instruction. In D. C. Berliner \& B. V. Rosenshine (Eds.), Talks to teachers (pp. 99-110). New York: Random House.

Berliner, D. C. (1992). The nature of expertise in teaching. In F. K. Oser, A. Dick, \& J. L. Patry (Eds.), Effective and responsible teaching: The new synthesis (pp. 227-248). San Francisco, CA: Jossey-Bass.

Connelly, G. (2010). Prekindergarten through grade three alignment: The role of the elementary principal in building and nurturing $a$ seamless continuum of learning. Alexandria, VA: National Association of Elementary School Principals.

Copple, C., \& Bredekamp, S. (2009). To be an excellent teacher. In C. Copple \& S. Bredekamp (Eds.), Developmentally appropriate practice in early childhood programs serving children from birth through age 8 (3rd ed., pp. 33-52). Washington, DC: NAEYC.

Epstein, A. S. (2007). The intentional teacher: Choosing the best strategies for young children's learning. Washington, DC: NAEYC.

Graue, M. E. (2006). This thing called kindergarten. In D. F. Gullo (Ed.), K Today: Teaching and Learning in the kindergarten year (pp. 3-10). Washington, DC: NAEYC.

Gullo, D. F. (2005). Understanding assessment and evaluation in early childhood education. New York: Teachers College Press.

Gullo, D. F. (2006). Assessment in kindergarten. In D. F. Gullo (Ed.), $K$ Today: Teaching and Learning in the kindergarten year (pp. 138-150). Washington, DC: NAEYC.

Hughes, K., \& Gullo, D. F. (2010). Joyful learning and assessment in kindergarten. Young Children, 3(65), 57-59.

Miller, E., \& Almon, J. (2009). Crisis in the kindergarten: Why children need play in school. College Park, MD: Alliance for Childhood.

NCES (National Center for Educational Statistics). (2008). All levels of education. In Digest of educational statistics, 2007 (NCES 2008-022). Online: www.nces.ed.gov/gprograms/digest/ d07/ch-1.asp.

Pianta, R. C. (2003). Standardized classroom observations from pre- $k$ to 3rd grade: A mechanism for improving access to consistently high quality classroom experiences and practices during the $P-3$ years. New York: Foundation for Child Development.

The National Institute for Early Education Research (NIEER 2008). (2008). The state of preschools 2008. New Brunswick, NJ: Rutgers University.

Tomlinson, H. B. (2009). Developmentally appropriate practice in the kindergarten year-ages 5-6: An overview. In C. Copple \& S. Bredekamp (Eds.), Developmentally appropriate practice in early childhood programs serving children from birth through age 8 (3rd ed., pp. 187-216). Washington, DC: NAEYC. 